\title{
A SOLUÇÃO DE CONTROVÉRSIAS TRANSCONSTITUCIONAIS A PARTIR E ALÉM DA TEORIA DA ARGUMENTAÇÃO
}

\author{
CORREIA, Alef Augusto Pereira ${ }^{1}$; OLIVEIRA, Eduardo Chagas ${ }^{2}$ \\ 1. Graduando em Direito, Universidade Estadual de Feira de Santana, e-mail: \\ alefcorreiafsa@gmail.com \\ 2. Orientador, Departamento de Ciências Humanas, Universidade Estadual de Feira de \\ Santana, e-mail: echagas@uefs.br
}

\author{
PALAVRAS-CHAVE: SOLUÇÃO DE CONTROVÉRSIAS; \\ TRANSCONSTITUCIONALISMO; TEORIA DA ARGUMENTAÇÃO
}

\section{INTRODUÇÃO}

Nos estudos realizados nesta obra analisei as decisões judiciais que têm efeitos divergentes na realidade social, tendo em vista que existe uma divergência no plano de exequibilidade. De um lado, um tribunal estatal decide a lide em determinado sentido; do outro lado, a corte supranacional toma uma decisão manifestamente contrária à decisão tomada anteriormente. Neste episódio, busquei apresentar as ideias gerais sobre o transconstitucionalismo, tese que defende a necessidade de um processo dialógico entre as cortes estatais e internacionais.

No primeiro capítulo, realizei uma construção teórico-metodológica do(s) problema(s) encarados nesta pesquisa. Estes pressupostos caminham desde a internacionalização dos problemas constitucionais, passando pela exposição dos motivos ensejadores dos problemas e chegando ao delineamento de perspectivas a serem abordadas.

Em seguida, considerei a teoria dos sistemas luhmanniana como modelo explicativo para a relação entre o direito e a sociedade. Desta relação, investigou-se a posição dos tribunais neste sistema, considerando os aspectos atinentes ao modo de interpretar e codificar os fatos sociais. Na sequência, analisamos per se a teoria da argumentação perelmaniana, estabelecendo os elementos necessários a este ensaio, bem como os aspectos sob os quais analisaria as decisões judiciais.

Concluindo, analisei de modo detalhado três decisões judiciais que se revelam importantes nesta obra. Primeiro, um caso envolvendo o Tribunal Constitucional Chileno e os direitos de exibição do filme "A última tentação de Cristo". Segundo, investiguei um caso sensível na realidade do Brasil, concernente a omissão do Estado brasileiro em investigar a morte dos guerrilheiros do Araguaia, sobretudo com o advento da Lei da anistia. Por fim, explorei um caso mais complexo, em que litigavam interesses do Estado brasileiro, com o Mercosul e a União Europeia no âmbito da Organização Mundial do Comércio, sobre a importação de pneus recauchutados. Por derradeiro, teci algumas considerações sobre a suficiência dos modelos argumentativos na experiência jurídica transconstitucional.

\section{MATERIAL E MÉTODOS OU METODOLOGIA (ou equivalente)}

O presente trabalho se configurou como uma investigação prevalentemente empírica, dedutiva/indutiva, qualitativa e de caráter analítico, contemplando o estudo e a avaliação das decisões associados ao problema da transversalidade da jurisdição constitucional, com o 
intuito de construir um modelo teórico de solução de controvérsias transconstitucionais a partir destes julgados. Para tanto, adotou-se o referencial da Teoria da Argumentação perelmaniana, sobretudo as premissas da argumentação destacadas na obra Recherches Interdisciplinaires Sur L',Argumentation.

Com isso, buscou-se fazer um movimento dedutivo da ideia de Ponto Cego em Niklas Luhmann e a noção de persuasão e convencimento na teoria perelmaniana para os casos concretos, agrupando os argumentos nos blocos de variáveis e, após, um movimento indutivo das variáveis coletadas no tocante à solução das controvérsias - bem como a efetividade destas soluções no campo prático - a um modelo teórico de solução de controvérsias transconstitucionais a partir das decisões em que litigam Cortes Constitucionais e Tribunais Internacionais/Supranacionais.

\section{RESULTADOS E/OU DISCUSSÃO (ou Análise e discussão dos resultados)}

Analisando o problema associado aos fatos sociais que transcendem a ordem jurídica estatal para o plano internacional, verificou-se que nas cortes internacionais existe uma noção de superioridade hermenêutica que justifica a imposição das decisões das cortes internacionais sobre a decisão das cortes estatais. Esta posição se verifica através da ratificação dos tratados e convenções internacionais, mas também por uma concepção internacionalista, segundo a qual o direito internacional deve prevalecer sobre os direitos estatais.

Em sentido formal, entretanto, este processo ocorre em um diálogo entre as cortes. Isso porque estas cortes não deixam de mencionar o trabalho realizado pelo Estado, fazendo movimentos de argumentação e contra-argumentação, configurando-se o diálogo entre as cortes.

Por esta razão, analisando o papel da teoria da argumentação neste procedimento, percebe-se a abordagem dos elementos: vontade ouvir, desejo de persuadir e deixar-se convencer-se. Mas o fator hermenêutico empregado a contrario sensu de uma perspectiva heterárquica lança dúvidas sobre a suficiência destes elementos. Constatou-se que o fator problemático - que não é explicado pela teoria da argumentação perelmaniana - é a noção do "ponto cego", obtemperada por Niklas Luhmann, em Direito da Sociedade. Este elemento se mostra fundamental para a solução de problemas transconstitucionais. E necessário que, pelo menos, uma das partes na lide reconheça que seu horizonte de contemplação não é suficiente para a solução do conflito, solução esta que só pode ser sanada pelo conhecimento que é trazido pelo olhar do outro.

Ainda que o processo seja dialógico, resta o problema da exequibilidade das decisões. Decisões contrárias continuam a gerar inadequações no plano fático. Assim, não se pode falar do controle de convencionalidade como expoente da Nova Retórica, pois o controle de convencionalidade não se configura como um modelo argumentativo/hermenêutico, mas sim uma aplicação normativa. De outro giro, também não se pode falar que o transconstitucionalismo se alinha a teoria da argumentação wittgensteiniana, considerando que "a rocha dura onde a pá entorta" nem sempre é fruto de um posicionamento bilateral, mas sim um reconhecimento de uma posição unilateral como verdadeira (vide Caroline de Mônaco vs. Alemanha). 
Neste sentido, uma teoria argumentação que concatenasse logicamente os elementos da teoria da argumentação perelmaniana, com a noção de ponto cego introduzida por Luhmann, seria um modelo explicativo mais adequado para solução de controvérsias transconstitucionais. A Corte Interamericana de Direitos Humanos, por exemplo, adota um sistema de solução de controvérsias pautado em um transconstitucionalismo. Isso porque as decisões prolatadas pela corte carregam amplo debate de argumentos com o Estado-parte na lide.

Esse problema acontece porque os juízes têm dificuldades de aceitar que possuem um ponto cego e que o entendimento de outro tribunal mostrou algo que antes não poderia ser visto. $\mathrm{Na}$ esteira, o direito observa os fatos em segunda ordem e partir destas informações produz códigos (cláusula operativa).

Assim, apenas um lado da realidade pode ser contemplado. Como superar esta obscuridade? Isto pode ser sanado a partir da introdução de um outro observador na dinâmica de análise. Fato é que este outro observador poderá perceber questões que não podiam ser vistas antes em razão de uma limitação natural do observador.

\section{CONSIDERAÇÕES FINAIS (ou Conclusão)}

Esta concepção representa uma possibilidade de sanar o problema da limitação no horizonte de contemplação dos tribunais. Assim, é necessário que as côrtes reconheçam que o ponto cego pode ser visto pelo outro. Isto importaria em decisões judiciais que reconhecessem os diferentes pontos de vista sobre o objeto de investigação, inclusive a própria incapacidade de perceber e entender determinados assuntos.

Esta construção é o cerne de uma proposta transconstitucional para a solução de conflitos nesta esfera: a necessidade de enfrentamento de problemas complexos mediante a articulação de observações recíprocas entre as diversas ordens jurídicas da sociedade mundial.

Por corolário, o Estado deve buscar a solução dialógica para os problemas, atentando para as consequências da decisão judicial, evitando os extremos do provincianismo e do internacionalismo, buscando uma solução pautada em conversações constitucionais, transconstitucionais.

\section{REFERÊNCIAS}

ALEXY, Robert. Teoria da Argumentação Jurídica: a teoria do discurso racional como teoria da fundamentação jurídica. $3^{\text {a }}$ Edição. Rio de Janeira: Forense, 2013.

JOSEFO, Flávio. História dos Hebreus. Rio de Janeiro: CPAD, 2006.

LUHMANN, Niklas. Legitimação pelo procedimento. Brasília: Universidade de Brasília, 1980.

LUHMANN, Niklas. El derecho de la sociedad. Herder/Universidad Iberoamericana, 2003.

LUHMANN, Niklas. La sociedad de la sociedad. México: Herder/Universidad Iberoamericana, 2007.

NEVES, Marcelo. Transconstitucionalismo. São Paulo: WMF Martins Fontes, 2009.

OLIVEIRA, Eduardo Chagas. A "nova retórica": da "regra de justiça" ao "ad hominem. Campinas, SP : IFCH/Unicamp, 2007. 
PERELMAN, Chaim. Recherches Interdisciplinaires Sur L',Argumentation. Congrès mondial de Sociologie, 1966.

PERELMAN, Chaim. Ética e Direito. São Paulo: Editora Martins Fontes, 1996.

PERELMAN, Chaim. Império Retórico: Retórica e argumentação. Porto: Asa, 1999a.

PERELMAN, Chaïm ; OLBRECHTS-TYTECA, Lucie. Tratado da Argumentação: A Nova Retórica. Trad.: Maria Ermantina Galvão. São Paulo: Martins Fontes, 1999b. ROCHA, Cármen Lúcia de Antunes. Relatório da Arguição de Descumprimento de Preceito Fundamental $n^{\circ}$ 101. Distrito Federal, Brasília: Supremo Tribunal Federal, 2009.

STRAUSS, Anselmo; CORBIN, Juliet. Pesquisa qualitativa: técnicas e procedimentos para o desenvolvimento de teoria fundamentada. $2^{\mathrm{a}}$ ed. Porto Alegre: Artmed; 2008.

VIOLA, Ricardo Rocha. Teoria da Decisão Judicial. Belo Horizonte: Editora D’Plácido, 2016.

WITTGENSTEIN, Ludwig. Investigações Filosóficas. São Paulo: Editora Nova Cultural, 1999. 